\title{
Use of EMW radiation in the building industry at defects in buildings
}

\author{
Jindřich Sobotka ${ }^{1, *}$ and Radim Smolka ${ }^{1}$ \\ ${ }^{1}$ Brno University of Technology, Faculty of Civil Engineering, \\ Institute of Building Structures, Veveř́ 95, 60200 Brno, Czech Republic
}

\begin{abstract}
This paper discusses theory and application of microwave radiation and experimental optimization of microwave radiation to eliminate moisture content in wood elements. It will be appreciated that the rising moisture leaking into the structure, resulting in defects and structures of the buildings themselves. Owing to its properties, microwave radiation has been used in the construction industry in modern times, in particular to dry wet masonry of buildings. Effects of electromagnetic radiation on building structures lead to relatively sharp decreases in moisture content from damp building structures or elements. The influence of electromagnetic radiation on building structures lead to oscillation of water molecules contained in the material, which cause a phase transformation of water into vapour. Consequently, the vapour evaporates from the moist material, thereby drying the element exposed to radiation. The article describes experiments carried out at the Faculty of Civil Engineering of the Faculty of Technology in Brno that demonstrate successful decrease of water content in building materials using microwave radiation. First, the understanding of microwave radiation will be discussed. Following an analysis of research results an optimum intensity of microwave radiation sources as well as the necessary length of the irradiation of microwave radiation have been determined with respect to the particular type of building material and the success rate of elimination of moisture.
\end{abstract}

\section{Introduction}

Microwaves are a term given to a part of electromagnetic radiation characterized by a wavelength ranging from $1 \mathrm{~cm}$ to 1 metre. In the form of waves the microwaves spread into space from the source. Worldwide, a frequency of $2.45 \mathrm{GHz}$ with a corresponding wavelength of $12.2 \mathrm{~cm}$ has been designated for industrial purposes [1].

\footnotetext{
* Corresponding author: sobotka.j@fce.vutbr.cz
} 


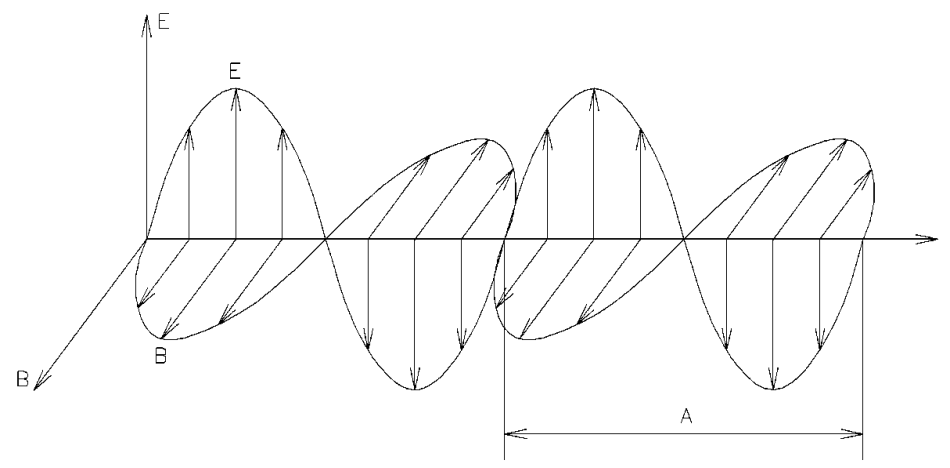

Fig. 1. Electromagnetic wave with the length $\lambda$ - electric (E) and magnetic (B) components of the wave [2].

\section{Drying by EMW Radiation}

The water molecules although having a bi-polar character are electrically neutral Therefore, in an electric field each and every water molecule is oriented by the polarity (positive to negative and negative to positive), especially if the polarity alternates. This is precisely the case of microwave radiation. The polarity of the electromagnetic field varies depending on the frequency $\mathrm{F}$, where the frequency can be higher than $10^{9}$ times per second [1].
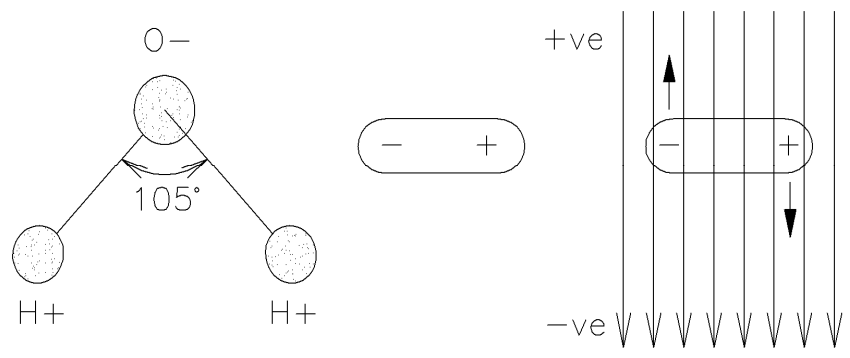

Fig. 2. Water molecule and its orientation in an electric field [2].

At high frequencies of radiation (i.e. oscillating vibration) and the subsequent change in orientation of molecules of loosely bound water produces heat. The thermal energy is produced by friction of molecules. This phenomenon is called as polar rotation or polar friction [3]. In a simple manner it can be described as follows, the entry of microwaves into the structures causes a rapid change in the polarity of molecules of loosely bound water, causing their rapid movement in the material. Because of this movement the particles themselves collide into each other, hence produce thermal energy. This process results in a conversion of water from liquid state into gaseous form, and its subsequent evaporation from the structure [4].

\subsection{Advantages and disadvantages of EMW heating and radiation}

The advantages of microwave radiation are:

- the so-called "Selective heating", i.e. by the radiation of multi-component structures only the materials absorbing microwave radiation are heated (i.e. materials containing loosely bound water),

- velocity of drying, 
- lower energy and financial requirements in comparison with hot-air drying.

The only known disadvantage of microwave radiation application is:

- the possibility of local overheating due to inhomogeneity of the microwave field and the material itself.

In terms of interaction of building material EMW radiation there are three possible outcomes. The material is either:

- transparent - radiation passes through the material without any reaction,

- absorbing - radiation is converted to thermal energy,

- reflecting - radiation is reflected back into the environment.

For building practice the interaction of microwaves with water is the most important factor. The conversion of microwave energy into thermal energy, heat can be determined using the following relationship [1], [5].:

$$
P=2 \cdot \pi \cdot f \cdot \varepsilon^{\prime} \cdot \varepsilon^{\prime \prime} \cdot E^{2}
$$

where: $\quad \mathrm{P}$ energy absorbed per unit volume $\left(\mathrm{W} \cdot \mathrm{m}^{-1}\right)$,

f frequency microwave field $(2450 \mathrm{MHz})$,

$\varepsilon^{\prime} \quad$ permittivity $\left(\mathrm{F} \cdot \mathrm{m}^{-1}\right)$,

$\varepsilon^{\prime \prime}$ dielectric loss factor of the material,

E electric field intensity inside the material $\left(\mathrm{V} \cdot \mathrm{m}^{-1}\right) .[1]$

\section{Material and methods}

One of a number of experiments carried out at the Faculty of Civil Engineering, Institute of Building Structures will be described in more detail. The aim was to determine the length and cyclic measurement of microwave radiation for a successful removal of moisture absorbed by wood elements [4].

\subsection{Description of the experiment}

Spruce lumber rectangular prisms of 220 by $160 \mathrm{~mm}$ were the irradiated wood elements used. The irradiated wooden prisms were cut-outs from wooden ceiling beams. In total, eight prisms of identical profiles were selected. The course of the experiment is described in the table, which also includes the standard deviation or radian. Prior to start of the experiment, each prism was weighed and measured for the appropriate surface and depth moisture content. The initial moisture content varied for the pieces. The different moisture of different elements prepared for the experiments varied from a number of aspects including porosity, proper cracks or volume stability. Inner temperatures of the experimental samples were checked and measured following every single irradiation cycle [1].

\subsection{Process of heating and drying}

3 cycles of 15 minutes. (15 min of irradiation, 120- minute break), Microwave emitter power: $750-800 \mathrm{~W}[1]$. 


\section{Results and discussion}

Following the final irradiation, the elements were left for 18 hours to allow free vaporization of accumulated water vapour. Next, moisture content and weight of the samples were analyzed and the obtained data were compared to initial values.

The entire process is caused by the way how the radiated energy created by a generator is absorbed. The radiated energy is first absorbed by the water molecules closest to the source of radiation. Thus after the first heating cycle the temperature went up only in a certain depth, the rest of the volume is then gradually warmed up by the subsequent cycles [1].

Similar results were then observed in case of the internal temperature then in case of the surface ones, after several cycles of radiation exposition [4]. The values of humidity were recorded at the beginning and also by the end of ongoing measurement process. From these findings it is evident, that not all samples behaved in the exact same manner. Some samples did have a higher moisture content on the obversed side in the final stages, which may be caused by the gradual extrusion of water vapor on the surface shows the initial, mid-time (after stale) and the final weight of exposed elements. As mentioned above, sample No.3 had a higher initial mass because of the rawness of sample.

On the microwave generator is represented together with a funnel waveguide, which were used for the exposition of wooden elements [6].

Table 1. Surface and depth temperatures.

\begin{tabular}{|c|c|c|c|c|c|c|c|c|}
\hline \multirow{2}{*}{\multicolumn{2}{|c|}{ Wood elements }} & \multicolumn{3}{|c|}{ Surface temperatures $\left[{ }^{\circ} \mathrm{C}\right]$} & \multirow{3}{*}{$\begin{array}{c}\begin{array}{c}\text { Inner } \\
\text { temperature }\end{array} \\
\mathrm{I}\end{array}$} & \multicolumn{3}{|c|}{ Temperature inside prism $\left[{ }^{\circ} \mathrm{C}\right]$} \\
\hline & & \multirow{2}{*}{$\begin{array}{c}\text { 1st heating } \\
98.9\end{array}$} & \multirow{2}{*}{$\begin{array}{c}\text { 2nd heating } \\
101.0\end{array}$} & \multirow{2}{*}{$\begin{array}{c}\text { 3rd heating } \\
106.0\end{array}$} & & \multirow{2}{*}{$\begin{array}{c}\text { 1st heating } \\
27.7\end{array}$} & \multirow{2}{*}{$\begin{array}{c}\text { 2nd heating } \\
62.9\end{array}$} & \multirow{2}{*}{$\begin{array}{c}\text { 3rd heating } \\
86.6\end{array}$} \\
\hline Prism & front & & & & & & & \\
\hline no. 1 & back & 27.2 & 37.1 & 51.4 & II & 31.7 & 74.4 & 94.7 \\
\hline \multirow{2}{*}{$\begin{array}{c}\text { Prism } \\
\text { no. } 2\end{array}$} & front & 96.5 & 106.0 & 95.1 & I & 27.0 & 58.4 & 95.1 \\
\hline & back & 18.1 & 31.2 & 53.1 & II & 30.2 & 64.8 & 97.2 \\
\hline \multirow{2}{*}{$\begin{array}{c}\text { Prism } \\
\text { no. } 3\end{array}$} & front & 84.2 & 98.0 & 98.9 & $\mathrm{I}$ & 16.6 & 37.2 & 48.5 \\
\hline & back & 15.9 & 20.5 & 30.6 & II & 49.8 & 45.4 & 58.4 \\
\hline \multirow{2}{*}{$\begin{array}{c}\text { Prism } \\
\text { no. } 4\end{array}$} & front & 97.2 & 99.8 & 105.1 & I & 26.2 & 57.1 & 93.7 \\
\hline & back & 25.3 & 36.2 & 49.5 & II & 28.7 & 61.8 & 95.2 \\
\hline \multirow{2}{*}{$\begin{array}{c}\text { Prism } \\
\text { no. } 5\end{array}$} & front & 94.3 & 97.5 & 101.7 & I & 23.3 & 54.6 & 91.4 \\
\hline & back & 16.4 & 27.8 & 49.2 & II & 25.1 & 58.5 & 92.7 \\
\hline \multirow{2}{*}{$\begin{array}{c}\text { Prism } \\
\text { no.6 }\end{array}$} & front & 95.1 & 104.6 & 106.3 & I & 27.8 & 59.4 & 96.3 \\
\hline & back & 17.3 & 29.2 & 51.1 & II & 30.6 & 63.8 & 98.2 \\
\hline \multirow{2}{*}{$\begin{array}{c}\text { Prism } \\
\text { no. } 7\end{array}$} & front & 97.8 & 100.5 & 106.2 & $\mathrm{I}$ & 26.7 & 58.2 & 94.3 \\
\hline & back & 26.1 & 37.4 & 51.6 & II & 28.1 & 61.9 & 96.2 \\
\hline \multirow{2}{*}{$\begin{array}{c}\text { Prism } \\
\text { no. } 8\end{array}$} & front & 96.2 & 105.1 & 94.9 & I & 27.1 & 58.8 & 95.3 \\
\hline & back & 17.6 & 29.2 & 51.1 & II & 30.3 & 65.1 & 96.7 \\
\hline \multirow{2}{*}{ Average $\bar{x}$} & front & 95.0 & 101.6 & 101.8 & $\mathrm{I}$ & 25.3 & 55.8 & 87.7 \\
\hline & back & 20.5 & 31.1 & 48.5 & II & 31.8 & 62.0 & 91.2 \\
\hline \multirow{2}{*}{ Median } & front & 96.4 & 100.8 & 103.4 & I & 26.9 & 58.3 & 94.0 \\
\hline & back & 17.9 & 30.2 & 51.1 & II & 30.3 & 62.9 & 95.7 \\
\hline \multirow{2}{*}{ Dispersion } & front & 18.6 & 9.4 & 21.1 & $\mathrm{I}$ & 12.6 & 54.2 & 227.2 \\
\hline & back & 20.2 & 29.0 & 46.8 & II & 49.8 & 57.8 & 155.8 \\
\hline \multirow{2}{*}{$\begin{array}{l}\text { Standard } \\
\text { deviation }\end{array}$} & front & 4.3 & 3.1 & 4.6 & $\mathrm{I}$ & 3.5 & 7.4 & 15.1 \\
\hline & back & 4.5 & 5.4 & 6.8 & II & 7.1 & 7.6 & 12.5 \\
\hline
\end{tabular}




\section{$98.9^{\circ} \mathrm{C}$}

\section{$\leftrightarrow F$ LIR}

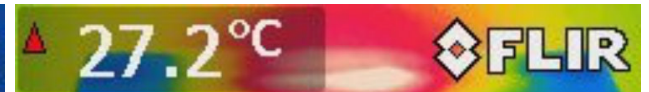

$18^{\circ} \mathrm{C}$
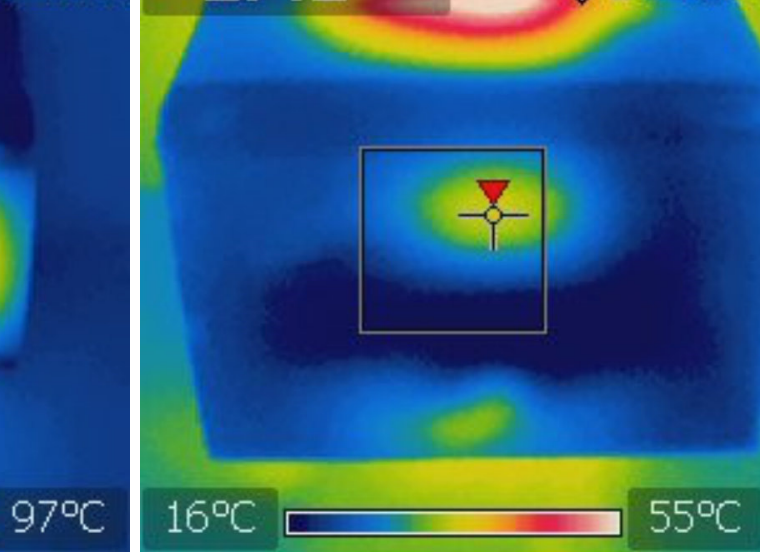

Fig. 3. Temperature field of the prism after the first heating from the back and the front.

Table 2. The moisture and weight values.

\begin{tabular}{|c|c|c|c|c|c|c|}
\hline \multirow{2}{*}{\multicolumn{2}{|c|}{ Wood elements }} & \multicolumn{2}{|c|}{ Moisture [\%] } & \multicolumn{3}{|c|}{ Weight [g] } \\
\hline & & \multirow{2}{*}{$\begin{array}{r}\text { Initial } \\
17.1\end{array}$} & \multirow{2}{*}{$\begin{array}{c}120 \text { minutes } \\
\text { after heating }\end{array}$} & \multirow{3}{*}{$\begin{array}{r}\text { Initial } \\
5754\end{array}$} & \multirow{3}{*}{$\begin{array}{c}\begin{array}{c}18 \text { hours } \\
\text { following } \\
\text { heating }\end{array} \\
5449\end{array}$} & \multirow{3}{*}{$\begin{array}{c}\text { Weight loss } \\
305\end{array}$} \\
\hline \multirow{2}{*}{$\begin{array}{c}\text { Prism } \\
\text { no. } 1\end{array}$} & front & & & & & \\
\hline & back & 18.1 & 14.9 & & & \\
\hline \multirow{2}{*}{$\begin{array}{c}\text { Prism } \\
\text { no. } 2\end{array}$} & front & 17.7 & 19.0 & \multirow{2}{*}{5887} & \multirow{2}{*}{5428} & \multirow{2}{*}{459} \\
\hline & back & 18.5 & 17.6 & & & \\
\hline \multirow{2}{*}{$\begin{array}{c}\text { Prism } \\
\text { no. } 3\end{array}$} & front & 18.5 & 16.9 & \multirow{2}{*}{7955} & \multirow{2}{*}{7318} & \multirow{2}{*}{637} \\
\hline & back & 22.0 & 20.0 & & & \\
\hline \multirow{2}{*}{$\begin{array}{c}\text { Prism } \\
\text { no. } 4\end{array}$} & front & 17.5 & 11.8 & \multirow{2}{*}{5782} & \multirow{2}{*}{5464} & \multirow{2}{*}{318} \\
\hline & back & 18.3 & 15.2 & & & \\
\hline \multirow{2}{*}{$\begin{array}{c}\text { Prism } \\
\text { no. } 5\end{array}$} & front & 18.1 & 19.7 & \multirow{2}{*}{5927} & \multirow{2}{*}{5489} & \multirow{2}{*}{438} \\
\hline & back & 18.9 & 18.3 & & & \\
\hline \multirow{2}{*}{$\begin{array}{c}\text { Prism } \\
\text { no.6 }\end{array}$} & front & 17.0 & 19.1 & \multirow{2}{*}{5836} & \multirow{2}{*}{5417} & \multirow{2}{*}{419} \\
\hline & back & 18.3 & 17.4 & & & \\
\hline \multirow{2}{*}{$\begin{array}{c}\text { Prism } \\
\text { no.7 }\end{array}$} & front & 17.2 & 11.4 & \multirow{2}{*}{5761} & \multirow{2}{*}{5435} & \multirow{2}{*}{326} \\
\hline & back & 18.3 & 15.1 & & & \\
\hline Prism & front & 17.9 & 19.3 & 5874 & 5447 & 427 \\
\hline no. 8 & back & 18.7 & 17.5 & $50 / 4$ & 3447 & 421 \\
\hline Average $\overline{-}$ & front & 17.6 & 16.1 & 60978 & 56809 & 4161 \\
\hline Average $\mathrm{A}$ & back & 18.9 & 17.0 & 0097.0 & 5080.9 & 410.1 \\
\hline Median & front & 17.6 & 18.0 & 58550 & 54480 & 4230 \\
\hline Miedian & back & 18.4 & 17.5 & 5855.0 & 5448.0 & 423.0 \\
\hline Disnersion & front & 0.2 & 13.2 & 4965080 & 3833154 & 101661 \\
\hline Dispersion & back & 1.4 & 2.8 & 490590.0 & 385315.4 & 10100.1 \\
\hline Standard & front & 0.5 & 3.6 & & & \\
\hline deviation & back & 1.2 & 1.7 & 104.1 & 019.1 & 100.8 \\
\hline
\end{tabular}




\section{Conclusions}

The aim of the experiment was to determine effects of higher initial moisture content of the irradiated material on the penetration of microwave energy and thus on the heating. Test specimens were taken from sawn wood in a so-called "raw" state [6].

As can be seen from the above tables, it has been determined experimentally that it is advantageous for the microwave drying of wood elements to use a lower microwave power and shorter irradiation cycles with longer pauses. This is due to the fact that during long irradiation cycles with higher performance and short breaks between radiation cycles large differences have been analysed between the temperatures on the front and back of the experimental prisms. Following final cooling, shape deformation and creation of additional drying cracks could be observed [1]. With those elements that were irradiated gradually, i.e. using lower microwave power, shorter drying cycles and longer breaks the increase in temperature was gradual, evaporation of water continued in a balanced manner and basically, any deformation of the wood element has been avoided.

In conclusion, the current results of experiments have found that cyclic microwave elimination of moisture in wood elements is effective. It is essential and highly effective to apply cyclic irradiation in the elimination of moisture in wood elements than the same period of time without a cyclic repetition. It is possible to conclude that irradiation using emitters with lower microwave power is fully effective and thus absolutely sufficient. Given the results of experimental work, significant and rapid elimination of weight and moisture has been achieved as compared with the initial and final values. The method of cyclic microwave drying of wood elements appears to be one of the most effective, fastest and thus the most economical methods for local and targeted reduction of moisture content in wood elements and building structures [1].

This paper has been worked out under the project No. LO1408 "AdMaS UP - Advanced Materials, Structures and Technologies", supported by Ministry of Education, Youth and Sports under the „National Sustainability Programme I".

\section{References}

1. M. Novotny, K. Suhajda, J. Sobotka, J. Gintar, E. Suhajdova, M. Matl, Wood ResSlovakia 59, 389-400 (2014)

2. D. Beckovsky, L. Vackova, T. Beckovska, J. Sobotka, J. Pencik, M. Lavicky, Wood Res-Slovakia 61, 627-636 (2016)

3. R. Smolka, T. Petricek, P. Kacalek, enviBUILD 2014 - Buildings and Environment (Brno, 2014)

4. M. Novotny, K. Suhajda, J. Sobotka, J. Gintar, AMR 1041, 297-302 (2014)

5. ČSN P 73 0610, Waterproofing of buildings (Czech Office for Normalization, Praha, 2000)

6. M. Novotny, J. Skramlík, K. Suhajda, J. Sobotka, AMR 688, 27-36 (2013) 